\title{
Complexity and Project Management: A General Overview
}

\author{
José R. San Cristóbal $\mathbb{D}^{1},{ }^{1}$ Luis Carral $\mathbb{D},{ }^{2}$ Emma Diaz, ${ }^{3}$ José A. Fraguela, $^{2}$ \\ and Gregorio Iglesias ${ }^{4}$ \\ ${ }^{1}$ Project Management Research Group, Universidad de Cantabria, Santander 39004, Spain \\ ${ }^{2}$ Department of Naval and Industrial Engineering, GEM, Universidade da Coruña, Ferrol 15403, Spain \\ ${ }^{3}$ Escuela Técnica Superior de Náutica, Universidad de Cantabria, Santander 39004, Spain \\ ${ }^{4}$ University of Plymouth, Plymouth, UK
}

Correspondence should be addressed to José R. San Cristóbal; jose.sancristobal@unican.es

Received 25 April 2018; Accepted 25 July 2018; Published 10 October 2018

Academic Editor: Roberto Natella

Copyright (c) 2018 José R. San Cristóbal et al. This is an open access article distributed under the Creative Commons Attribution License, which permits unrestricted use, distribution, and reproduction in any medium, provided the original work is properly cited.

\begin{abstract}
As projects have become more and more complex, there has been an increasing concern about the concept of project complexity. An understanding of project complexity and how it might be managed is of significant importance for project managers because of the differences associated with decision-making and goal attainment that are related to complexity. Complexity influences project planning and control; it can hinder the clear identification of goals and objectives, it can affect the selection of an appropriate project organization form, or it can even affect project outcomes. Identifying the different concepts associated to project complexity, its main factors and characteristics, the different types of project complexity, and the main project complexity models, can be of great support in assisting the global project management community. In this paper, we give a general overview of how complexity has been investigated by the project management community and propose several ideas to address this topic in the future.
\end{abstract}

\section{Introduction}

The origins of complexity theory applied to project management can be traced back to the works by Morris [1,2], Bennet and Fine [3], Bubshait and Selen [4], Bennet and Cropper [5], Gidado [6], Wozniak [7], and Baccarini [8]. All these works highlight the importance of complexity in project contexts in general and in particular its effects on project goals and objectives, project organization form and arrangement, and in the experience requirements for the management personnel.

The importance of complexity to the project management process is widely acknowledged for several reasons [1-8]: (i) it influences project planning, coordination, and control; (ii) it hinders the clear identification of goals and objectives of major projects; (iii) it can affect the selection of an appropriate project organization form and experience requirements of management personnel; (iv) it can be used as criteria in the selection of a suitable project management arrangement; and (v) it can affect different project outcomes (time, cost, quality, safety, etc.).

An understanding of project complexity and how it might be managed is of significant importance for project managers because of the differences associated with decision-making and goal attainment that appear to be related to complexity $[8,9]$. As projects have become more and more complex, there has been an increasing concern about the concept of project complexity and the application of traditional tools and techniques developed for simple projects has been found to be inappropriate for complex projects $[1,8]$. According to Parsons-Hann and Liu [10], it is evident that complexity contributes to project failure in organizations; what is not clear is to what degree this statement holds true. Identifying and characterizing different aspects of project complexity in order to understand more efficiently the stakes of project management complexity can be of great support in assisting the global project management community. 
Complexity can have both a negative and a positive influence on projects. The negative influence, in terms of difficulty to be understood and controlled, is because of the emergence of new properties that none of the elements of the system owns. The positive influence is due to the apparition of phenomena that could not be predicted due to the sole knowing, even complete, of the behaviour and interactions of the elements of the system. In order to properly manage complexity, project managers must know how to seize the opportunities emerging from complexity and to know how to avoid or at least diminish the negative effects of complexity [11].

In this paper, we give a general overview of how complexity, which is the main purpose of this special issue, has been addressed to date in the project management literature. We begin by discussing the different definitions of complexity in project contexts. Next, a summary of the project complexity factors and characteristics is presented. Then, the different types of project complexity and the main project complexity models are presented. Finally, the current and the future management approaches to address this topic in the future are proposed.

\section{Definitions of Project Complexity}

In project contexts, there is a lack of consensus on what complexity really is [12-20]. There does not even seem to be a single definition of project complexity that can capture the whole concept [11, 20-24]. Within the Luhmannian system theory, complexity is the sum of the following components [25]: differentiation of functions between project participants, dependencies between systems and subsystems, and the consequential impact of a decision field. Project complexity can also be interpreted and operationalized in terms of differentiation (number of elements in a project) and interdependencies and connectivity (degree of interrelatedness between these elements), which are managed by integration, that is, by coordination, communication, and control [1, 8, 26-29]. Custovic [30] defines complexity as that property of a system which makes it difficult to formulate its overall behaviour in a given language, even when given reasonable complete information about its atomic components and their interrelations. In a similar context, Vidal and Marle [11] define project complexity as that property of a project which makes it difficult to understand, foresee, and keep under control its overall behaviour. Tatikonda and Rosenthal [31] view complexity as consisting of interdependencies among the product and process technologies and novelty and difficulty of goals. Pich et al. [32] define complexity as information inadequacy when too many variables interact. Ward and Chapman [33] view the number of influencing factors and their interdependencies as constituents of complexity.

Some authors associate complex or complicated projects with the number of elements and with the concept of linearity. Girmscheid and Brockmann [34] argue that any difference between a complicated project and a complex project has to do with the number of elements as opposed to the relationships between the elements (complex). Richardson
[35] associates linearity with complicated projects and nonlinearity with complex projects, which implies that nonlinearity makes the relationship between inputs and outputs unpredictable. Remington et al. [9] defines a complex project as one that demonstrates a number of characteristics to a degree or level of severity that makes it extremely difficult to predict project outcomes, to control or manage the project. Girmscheid and Brockmann [34] define project complexity as a set of problems that consists of many parts with a multitude of possible interrelations, most of them being of high consequence in the decisionmaking process that brings about the final result.

\section{Project Complexity Factors and Characteristics}

Experience suggests that the interrelationships between the project's components are more complex than is suggested by the traditional work breakdown structure of project network. Identifying the sources and factors that contribute or increase project complexity is paramount for project managers. Gidado [36] determines four different sources of complexity: employed resources, environment, level of scientific and technological knowledge required, and number of different parts in the workflow. Thus, a large amount of required resources, a turbulent environment, working on the edge of technology, and innumerable possible interactions are certainly identifiable factors for complex projects.

Since there has been a lack of consensus and difficulty in defining complexity, some authors have focused on identifying the factors that contribute or increase project complexity. Remington et al. [9] suggest to differentiate between dimensions, characteristics, or sources of complexity, and severity factors, those factors that increase or decrease the severity of complexity. Vidal and Marle [11] consider the following factors as necessary but nonsufficient conditions for project complexity: size, variety, interdependences and interrelations within the project system, and context dependence. Remington et al. [9] group a number of factors that seem to contribute to the perception of project complexity under the following headings: goals, stakeholders, interfaces and interdependencies, technology, management process, work practices, and time. Table 1 shows the main factors that are considered in the literature as drivers of project complexity.

3.1. Size. Size has traditionally been considered the primary cause of complexity in organizations [37-40]. However, to consider size an indication of complexity, the organizational structure of a system should be over a minimum critical size and their elements need to be interrelated [41]. Substantial relationships have been found in both cross-sectorial and longitudinal studies in many different samples of organizations between size and various components of complexity such as personal specialization, division of labor, and structural differentiation [38]. A large number of studies have found that size is related to structural differentiation, but the relationship between size and complexity is less clear [37, 40, 42] . According to a study performed by Beyer and Trice [38] on several departments of the US governments, size is a more 
TABLE 1: Main factors affecting project complexity.

\begin{tabular}{|c|c|}
\hline Factor & \\
\hline Size & $\begin{array}{c}\text { To consider it an indication of complexity, the organizational structure of the project should be over } \\
\text { a minimum critical size and their elements need to be interrelated. }\end{array}$ \\
\hline Interdependence and interrelations & $\begin{array}{l}\text { An event in an interconnected structure can cause totally unknown effects on another entity inside } \\
\text { the structure. }\end{array}$ \\
\hline Goals and objectives & They must be adequately and properly defined both at a strategic and at an operational level. \\
\hline Stakeholders & $\begin{array}{l}\text { The number of project participants and how the information flows between them are a key factor } \\
\text { affecting project complexity. }\end{array}$ \\
\hline Management practices & $\begin{array}{l}\text { Relationships between project participants, suppliers, overlapping of activities, methods, and } \\
\text { techniques are factors that affect project complexity. }\end{array}$ \\
\hline Division of labor & $\begin{array}{l}\text { Adding project organizational structure by dividing labor, the way for personnel selection, and } \\
\text { the level of pressure on this personnel to achieve project objectives are factors that increase } \\
\text { project complexity. }\end{array}$ \\
\hline Technology & $\begin{array}{l}\text { Task scope or the variety of tasks that need to be accomplished is the most critical dimension of } \\
\text { technology. It explains why there is a need for a variety of technologies and a given level } \\
\text { specialization in each of them. }\end{array}$ \\
\hline Concurrent engineering & $\begin{array}{l}\text { It breaks down functional and departmental barriers by integrating team members with different } \\
\text { discipline backgrounds often known as cross-functional teams. }\end{array}$ \\
\hline Globalization and context dependence & $\begin{array}{l}\text { Globalization boots complexity by the erosion of boundaries, higher mobility, heterarchy, and } \\
\text { higher dynamics. It can be an essential feature of complexity. }\end{array}$ \\
\hline Diversity & A higher number of elements and a higher variety across elements increase complexity. \\
\hline Ambiguity & It expresses uncertainty of meaning in which multiple interpretations are plausible. \\
\hline Flux & $\begin{array}{c}\text { Flux is affected by external and internal influences. It also implies constant change and adaptation to } \\
\text { changing conditions. }\end{array}$ \\
\hline
\end{tabular}

important predictor of complexity while in a similar study from state employment agencies, Blau and Schoenherr [37] found that division of labor is a more important predictor of complexity.

3.2. Interdependence and Interrelations. It creates a link or influence of different types between entities in such a way that an event in an interconnected structure can cause totally unknown effects on another entity inside the structure [43]. The number of systems and subsystems that integrate the project, the different methodological and philosophical assumptions across these systems, the crossorganizational and schedule interdependencies between activities, the upgrading and retrofitting works, and the sheer size and entanglement in the project are all key factors influencing complexity.

3.3. Goals and Objectives. Goals and objectives must be adequately and properly defined, both at a strategic and at an operational level. In addition, all project participants including owners, managers, contractors, and consultants must be clear about these goals and objectives.

3.4. Stakeholders. The number of project participants and how the information flows between them are a key factor affecting project complexity. If the project is politically sensitive and of high visibility, project complexity can considerably be increased. Managing conflicting agendas of various stakeholder management strategies and processes, which is linked to structural complexity, can also amplify the complexity of a project.
3.5. Management Practices. Organizational and interactive management is one of the riskiest parts of a project. Contractor relationships and ethics, supplier monopolies, overlapping of processes and activities, methodologies, and techniques based on either hard or soft approaches that can affect the degree of definition of project goals and objectives are all factors that can influence project complexity.

3.6. Division of Labor. Dividing labor into distinct tasks and coordinating these tasks define the structure of an organization [44]. Adding project organizational structure by dividing labor into smaller and more specialized tasks, the way for personnel selection, and the level of pressure on the personnel to achieve project objectives are all factors that can increase project complexity.

3.7. Technology. Broadly speaking, technology can be defined as the transformation process which converts inputs into outputs using materials, means, techniques, knowledge, and skills $[8,26]$. The most critical dimension of technology is the variety of tasks that need to be accomplished, what is sometimes called task scope and is proposed as a determinant of horizontal differentiation [42]. It explains why there is a need for a variety of technologies and a given level specialization in each of them. Baccarini [8] proposes to define technological complexity in terms of differentiation and interdependencies. Technological complexity by differentiation refers to the variety and diversity of some aspects of a task such as number and diversity of inputs/outputs, number and diversity of tasks to undertake, and number of specialities and contractors, involved in the project. 
Technological complexity by interdependency encompasses interdependencies between tasks, within a network of tasks, between teams, between different technologies, and between inputs (technological interdependence can be one of three types, pooled, sequential, and reciprocal, with reciprocal interdependency the prevalent type in construction projects).

3.8. Concurrent Engineering. The ever increasing pressure to execute projects more rapidly has led many companies to deploy project organizations comprised of distributed and often outsourced teams and in many cases to execute concurrently many activities [45]. Concurrent Engineering breaks down functional and departmental barriers by integrating team members with different discipline backgrounds often known as cross-functional teams [46]. This process requires changes in the organizational structure and a more vigorous communication, coordination, and collaboration [47].

3.9. Globalization and Context Dependence. Globalization boots complexity by the erosion of boundaries, higher mobility, heterarchy, and higher dynamics [46]. The context and environment under which the project is undertaken can be an essential feature of complexity. In fact, the methods and practices applicable to a project may not be directly transferable to other projects with different institutional, language, and cultural configurations.

3.10. Diversity. Diversity is defined as the plurality of elements. It encompasses two components, the number of elements (multiplicity) and their dissimilarity (variety). A higher number of elements and a higher variety across elements increase complexity.

3.11. Ambiguity. Ambiguity can be defined as too much information with less and less clarity on how to interpret and apply findings [43]. Ambiguity expresses uncertainty of meaning in which multiple interpretations are plausible which leads to the existence of multiple, often conflicting situations, goals, and processes [46].

3.12. Flux. Flux implies constant change and adaptation to changing conditions making temporary solutions regarding interdependence, diversity, and ambiguity outdated from one day to another [48]. Flux is affected by external and internal influences. External influences can either be political or market-related changes, while internal influences come from changes in strategy, in individual behaviour, etc.

\section{Types of Project Complexity}

Bosch-Rekveldt et al. [16] conducted an online survey using the TOE framework (technical, organizational, and environmental) and came to determine the position of the respondents about the nature of the complexity of the organization in engineering projects. They concluded that project managers were more concerned with organizational complexity than technical or environmental complexities. Vidal and Marle [11] argued that approximately $70 \%$ of the complexity factors of the project are organizational. This seems to be in line with Baccarini's [8] opinion on organizational complexity which, according to him, is influenced by differentiation and operative interdependencies.

According to Vidal and Marle [11], there are historically two main approaches of complexity. The one, usually known as the field of descriptive complexity, considers complexity as an intrinsic property of a system, a vision which invited researchers to try to quantify or measure complexity. The other one, usually known as the field of perceived complexity, considers complexity as subjective, since the complexity of a system is improperly understood through the perception of an observer. For all practical purposes, a project manager deals with perceived complexity as he cannot understand and deal with the whole reality and complexity of the project. According to this perceived complexity, project managers make the corresponding decisions and take the corresponding actions to influence the project evolution and reach the desired project state $[11,49]$.

How complexity is perceived and interpreted by project managers may result in different types of project complexity. Baccarini [8] considers technological and organizational complexities as the core components of project complexity. According to $[25,34]$, four different types of project complexity, overall, task, social, and cultural, help to best understand and prevent projects from failure. Task complexity refers to the density of the units, causal links, and consequences within a temporal and spatial frame. Social complexity describes the number of members communicating and working with each other and the differentiation of their tasks, while cultural complexity encompasses the number of different historical experiences and sense-making processes that confront each other in a project. Cultural complexity compresses the history, experience, and sense-making processes of different groups that joint the effort in a project. Overall and task complexity can be managed by a functional organization with decentralized decision-making and social complexity by trust and commitment, whereas cultural complexity by sense-making processes.

Pollack and Remington and Pollack $[50,51]$ emphasize that a clear distinction on the type of complexity helps in selecting the appropriate model to manage a project. Based on the source of complexity, the authors suggest four types of project complexity: structural, technical, directional, and temporal complexity. Structural complexity stems from large-scale projects which are typically broken down into small tasks and separate contracts. Projects in the engineering, construction, IT, and defence sectors where the complexity stems from the difficulty in managing and keeping track of the high number of interconnected tasks and activities are likely to have this type of complexity [51]. Technical complexity is found in architectural, industrial design, and R\&D projects which have design characteristics or technical aspects that are unknown or untried and where complexity arises because of the uncertainty regarding the outcome for many independent design solutions [51]. Baccarini [8] categorizes technological complexity in terms of differentiation and interdependence, which is further categorized into three types given in an ascending order of complexity: (i) pooled, in which each element gives a discrete contribution to the 
project; (ii) sequential, where one element's output becomes another's input; and (iii) reciprocal, where each element's output becomes inputs for other elements [51, 52]. Directional complexity is often found in change projects where the direction of the project is not understood and when it is clear that something must be done to improve a problematic situation [51]. Temporal complexity results in projects where due to unexpected legislative changes of rapid changes in technology, there is a high level of uncertainty regarding future constraints that could destabilize the project. Operative complexity, i.e., the degree to which organizations of the project are independent when defining their operations to achieve given goals, and cognitive complexity which identifies the degree to which self-reflection, sense-making processes, the emergence of an identity, or even an organizational culture is possible, are also different types of complexity identified in the literature [36].

\section{Project Complexity Models}

Trying to find the most appropriate model for managing a project can be a difficult task. If the model is too simple, it is not enough close to reality. On the contrary, if it is too complex, it can be useless to project managers. Next, some of the most relevant complexity models in the project management literature will be revised.

5.1. Goals and Methods Matrix. Based on how well-defined are the goals and methods of achieving these goals in a project, Turner and Cochrane [53] developed the goals and methods matrix shown in Figure 1 where four types of projects can be found: (i) type 1 projects are projects in which goals and methods are well-defined and understood. In this case, the role of the project manager is that of a conductor; (ii) type 2 projects are projects with well-defined goals but poorly defined methods. In this case, the role of the project manager is that of a coach; (iii) type 3 projects are projects planned in life-cycle stages with poorly defined goals but well-defined methods; and (iv) type 4 projects are projects with no defined goals and no defined methods. Typically, engineering and construction projects fall within the category of type 1 projects. Product development projects belong to type 2, while application software development and R\&D and organizational change projects belong to type 3 and type 4 projects, respectively.

5.2. Stacey's Agreement and Certainty Matrix. Stacey [54] analysed complexity on two dimensions, the degree of certainty and the level of agreement and, based on these two dimensions, developed the matrix shown in Figure 2 with the following zones: (i) close to agreement, close to certainty: in this zone, we can find simple projects where traditional project management techniques work well and the goal is to identify the right process to maximize efficiency and effectives; (ii) far from agreement, close to certainty: in this case, coalitions, compromise, and negotiation are used to solve this type of situations; (iii) close to agreement, far from certainty: in this case, traditional project management techniques may not work and leadership approaches must be

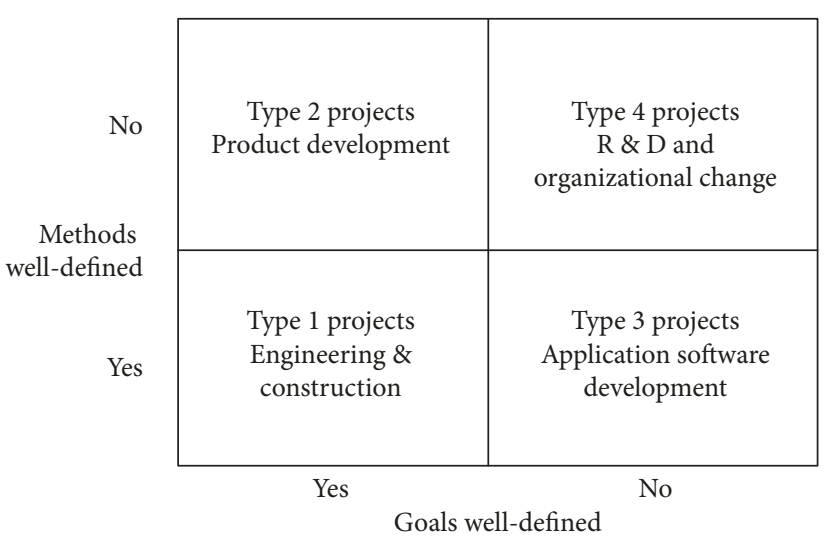

FIgURE 1: Goals and methods matrix [53].

used to solve this type of situations; and (iv) far from agreement far from certainty: this is the zone of anarchy with a high level of uncertainty and where traditional management techniques will not work.

5.3. William's Model. Williams and Hillson [55] extend Baccarini's model by one additional dimension. In addition to the two components of complexity suggested by Baccarini, i.e., the number of elements and the interdependency of these elements, the authors introduce uncertainty and attributes the increasing complexity in projects to two compounding causes, the relationship between product complexity and project complexity and the length of projects. The resulting model is shown in Figure 3 where, as can be seen, project complexity is characterized by two dimensions, structural complexity and uncertainty, each of one having two subdimensions, number and interdependency of elements, and uncertainty in goals and methods, respectively.

5.4. Kahane's Approach. Kahane's [56] approach to complexity is deeply rooted in a social environment. He introduces the U-process as a methodology for addressing complex challenges and distinguishes complexity in three ways: (i) dynamic complexity: the cause and effect of complexity are far apart and it is hard to grasp from first-hand experience; (ii) generative complexity: a situation where the solution cannot be calculated in advance based only on what has worked in the past; and (iii) social complexity: the people involved who have different perspectives and interests must participate in creating and implementing the solution. When using the U-process developed by Kahane [56], project managers undertake three activities: (i) sensing the current reality of the project; (ii) reflecting about what is going on and what they have to do; and (iii) realizing and acting quickly to bring forth a new reality.

5.5. Cynefin Decision-Making Framework. Snowden and Boone [57] developed the Cynefin framework, which allows executives to see new things from new viewpoints, assimilate complex concepts, and address real-world problems and opportunities. The framework sorts it into five domains, simple, complicated, complex, chaotic, and disorder, each 


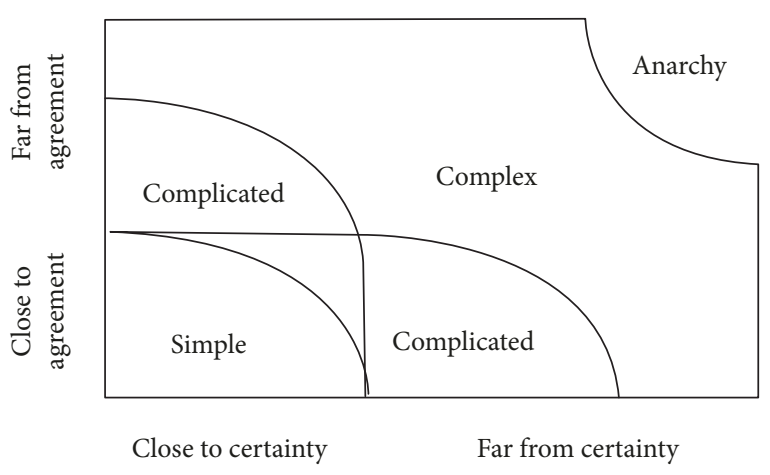

FIgURE 2: Agreement and certainty matrix [54].

of one requires different actions based on cause and effect. The simple and complicated domains are characterized by cause and effect relationships, and right answers can be determined based on facts. The complex and chaotic domains do not have a clear cause and effect relationship, and decisions must be made based on incomplete data. The last domain, disorder, is applied when it is unclear which of the four is dominant and is tackled by breaking it down into smaller components and then assigning them to the other four domains. Table 2 shows the characteristics of each context, the leader's job, the danger signals, and the response to these danger signals [57].

5.6. The UCP Model. The UCP model classifies projects according to uncertainty, complexity, and pace. Furthermore, uncertainty has been broken down into four levels of technological uncertainty (low-, medium-, high-, and super high-technology projects). Complexity into three levels of system scope is based on a hierarchy of systems and subsystems (assembly, system, and array) and pace into three levels (regular, fast-competitive, and critical-blitz projects) [58-60]:

(a) The technological dimension

(i) Low-Technology Projects. Projects based on existing and well-established technologies

(ii) Medium-Technology Projects. Projects based mainly on existing technologies but incorporating a single new technology or feature

(iii) High-Technology Projects. Projects that integrate a collection of new but existing technologies

(iv) Super High-Technology Projects. Projects based on non-yet existing technologies in which, although the project goal is clear, no technology is known to achieve the final product

(b) The system scope dimension (complexity)

(i) Scope 1: Assembly. A collection of components in a single unit, performing a well-defined limited function (ii) Scope 2: System. A complex collection of interactive units jointly performing a wide range of functions

(iii) Scope 3: Array. A large collection of systems functioning together to achieve a common purpose

(c) The pace dimension

(i) Regular Projects. Projects that, although confined to a limited time-frame, still can achieve their objectives

(ii) Fast-Competitive Projects. Projects conceived to create strategic positions, address market opportunities, etc. In this type of projects, since time to market is directly associated with competitiveness, missing the deadline might not be fatal but it could hurt competitive positions

(iii) Critical-blitz projects are the most urgent and most time-critical projects in which meeting schedule is critical to success and project delay means project failure.

\section{Current and Future Approaches to Manage Complexity}

Understanding how project managers deal with the different types of complexity and how they reply to these different types can help to prevent projects from failure. Stacey [54], Kahane [56], and Snowden and Boone [57] focus on how complexity, particularly messy or ill-structured problems, might influence leadership style and decision-making in periods of organizational change. Clift and Vandenbosch [61], in a survey conducted with project manager leaders of new product development teams, found that long-cycle complex projects were run by autocratic leaders, adhered to a well-defined standardized, serial processing approach. In contrast, short-cycle complex projects were run by project managers who used a more participative management style with many external sources of information.

Project complexity has been addressed by researchers from different perspectives and approaches. Early methods from the general management literature include Declerck and Eymery's [62] method for analysing ill-structured problems and Turner and Cochrane's goals and methods matrix [53]. Part of the literature has focused on uncertainty $[32,63]$. Williams [64] views the number of elements and their interrelationships as constituents of structural uncertainty which is proposed as an element of complexity. Shenhar [65] regards complexity and uncertainty as orthogonal to each other. Atkinson et al. [66] considers complexity as an element of uncertainty while Geraldi et al. and Müller et al. $[17,67]$ support uncertainty as an element of complexity. Perminova et al. [68] equate complexity to systematic uncertainty. Pich et al. [32] associate categories of uncertainty with variations, foreseen uncertainty, unforeseen uncertainty, and chaos. Sommer and Loch [12] treat complexity and unforeseeable uncertainty as separate constructs. 


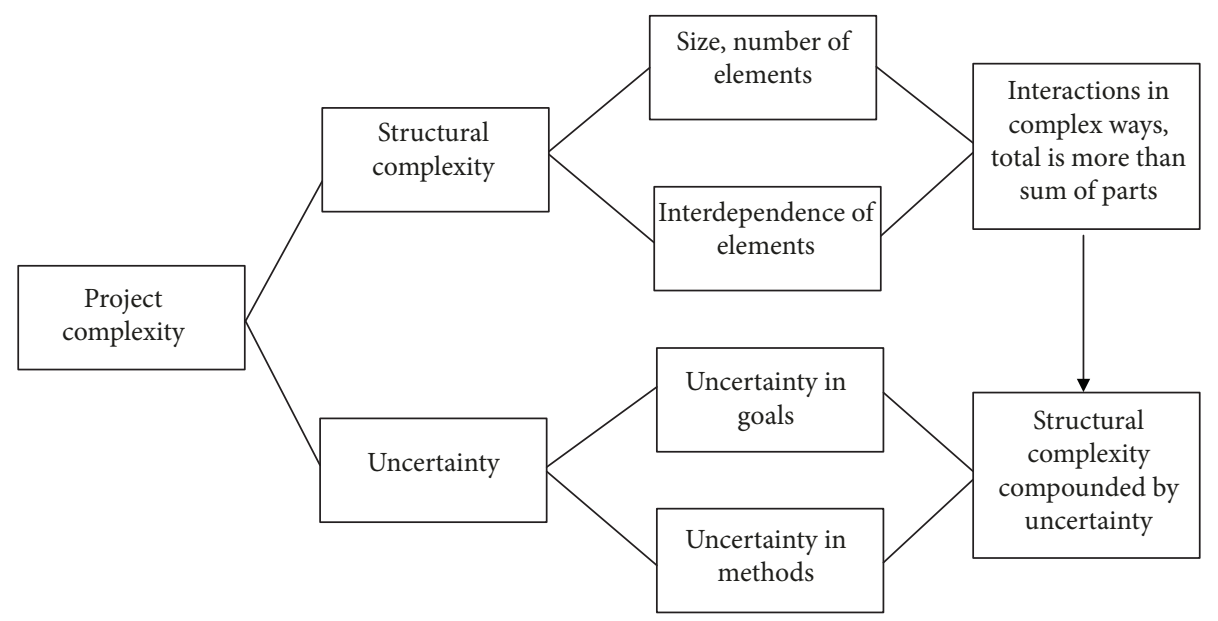

FIgURE 3: William's model [55].

TABLE 2: Context's characteristics, leader's job, danger signals, and response to danger signals.

\begin{tabular}{|c|c|c|c|c|}
\hline & Context's characteristics & Leader's job & Danger signals & Response to danger signals \\
\hline Simple & $\begin{array}{c}\text { Repeating patterns } \\
\text { Clear cause-and-effect } \\
\text { relationships } \\
\text { Known knowns } \\
\text { Fact-based management }\end{array}$ & $\begin{array}{l}\text { Sense, categorize, respond, } \\
\text { and delegate } \\
\text { Use best practices } \\
\text { Communicate in clear and } \\
\text { direct ways }\end{array}$ & $\begin{array}{c}\text { Complacency and comfort } \\
\text { Make simple problems } \\
\text { complex } \\
\text { Entrained thinking }\end{array}$ & $\begin{array}{l}\text { Create communication channels } \\
\text { Do not assume things are simple } \\
\text { Recognize both the value and } \\
\text { limitations of best practice }\end{array}$ \\
\hline Complicated & $\begin{array}{l}\text { Expert diagnosis required } \\
\text { Cause-and-effect } \\
\text { relationships not } \\
\text { immediately apparent } \\
\text { Known unknowns } \\
\text { Fact-based management }\end{array}$ & $\begin{array}{l}\text { Sense, analyse, and respond } \\
\text { Create panels of experts } \\
\text { Listen to conflicting } \\
\text { objectives }\end{array}$ & $\begin{array}{l}\text { Experts overconfident in } \\
\text { their own solutions } \\
\text { Analysis paralysis } \\
\text { Viewpoints of nonexperts } \\
\text { excluded }\end{array}$ & $\begin{array}{l}\text { Encourage external and internal } \\
\text { stakeholders to challenge } \\
\text { expert opinions } \\
\text { Use experiments and games } \\
\text { to force people to think outside } \\
\text { the familiar }\end{array}$ \\
\hline Complex & $\begin{array}{c}\text { Flux and unpredictability } \\
\text { No right answers } \\
\text { Unknown unknowns } \\
\text { Many competing ideas } \\
\text { A need for creative and } \\
\text { innovative approaches } \\
\text { Pattern-based leadership }\end{array}$ & $\begin{array}{l}\text { Probe, sense, and respond } \\
\text { Create environments and } \\
\text { experiments that allow } \\
\text { patterns to emerge } \\
\text { Increase levels of interaction } \\
\text { and communication } \\
\text { Use methods that can } \\
\text { generate ideas }\end{array}$ & $\begin{array}{l}\text { Temptation to fall back } \\
\text { into habitual, command- } \\
\text { and-control model } \\
\text { Desire for accelerated } \\
\text { resolution of problems }\end{array}$ & $\begin{array}{l}\text { Allow time for reflection } \\
\text { Use approaches that encourage } \\
\text { interaction so patterns } \\
\text { can emerge }\end{array}$ \\
\hline Chaotic & $\begin{array}{c}\text { High turbulence } \\
\text { No clear cause-and-effect } \\
\text { relationships } \\
\text { Unknowables } \\
\text { High tension } \\
\text { Many decisions to make and } \\
\text { no time to think } \\
\text { Pattern-based leadership }\end{array}$ & $\begin{array}{l}\text { Act, sense, and respond } \\
\text { Look for what works instead } \\
\text { of seeking right answers } \\
\text { Take immediate action to } \\
\text { reestablish order } \\
\text { Provide clear and direct } \\
\text { communication }\end{array}$ & $\begin{array}{l}\text { Applying a command- } \\
\text { and-control approach } \\
\text { longer than needed } \\
\text { Missed opportunity for } \\
\text { innovation } \\
\text { Chaos unabated }\end{array}$ & $\begin{array}{l}\text { Set up mechanisms to take } \\
\text { advantage of the opportunities } \\
\text { afforded by a chaotic } \\
\text { environment } \\
\text { Work to shift the context to } \\
\text { chaotic to complex }\end{array}$ \\
\hline
\end{tabular}

Williams [69] defines two additional types of uncertainty, aleatoric uncertainty relating to the reliability of calculations and existence uncertainty stemming from lack of knowledge and leading to project complexity.

Other approaches used to deal with complexity in project management contexts include systems theory to help understand how different aspects affect the project as a system $[8,51,55]$. Payne [70] takes a perspective which combines difficulty and systems thinking, associating complexity with the multiple interfaces between individual projects, the organization, and the parties concerned. Laufer et al. [71] explore the evolution of management styles associated with the organizational complicacy of simple and complex projects. Tatikonda and Rosenthal [31] and Pundir et al. [72] relate technological novelty to technological maturity of the organization; immaturity leads to task uncertainty.

The increasingly fast-paced systems of today's business and social environment, characterized by discontinuity and change, force organizations to make decisions and take the corresponding actions based on multiple unknown variables. 
According to Pundir et al. [72], since projects exhibit the characteristics of complex systems, the method to manage them cannot be predicted in advance, it will emerge from the interactions between the project elements and the environment. Richardson [35] explores the implications of complexity from the management of organizations and how "thinking complexity" may affect the way in which project managers do their jobs. According to the author, if there are limits to what we can know about our organization, there are limits to what we can achieve in a predetermined and planned way. H. Singh and A. Singh [73] argue that it is at the edge of chaos, where linear systems begin to fail and nonlinear systems begin to dominate and where project managers must begin to pay greater attention to the nonlinear and subtle influences in their planning and management styles.

\section{Conclusions}

When problems fundamentally dynamic are treated statically, delays and cost overruns are common. Traditional project management tools and techniques, based on the assumptions that a set of tasks can be discrete, with welldefined information about time, cost, and resources, and with extensive preplanning and control, are often found inadequate. These traditional approaches that utilize a static approach provide project managers with unrealistic estimations ignoring multiple feedback processes and nonlinear relationships of the project. The interrelationships between the components of a project are more complex that is suggested by traditional techniques, which makes them inadequate to the challenges of today's dynamic project environment.

The new complex and dynamic environments require project managers to rethink the traditional definition of a project and the ways to manage it. Project managers must be able to make decisions in these dynamic yet unstable systems that are continuously changing and evolving in a random fashion and are hard to predict, very different from the linear, predictable systems traditionally studied. To achieve this objective, more integrated approaches for managing projects in complex environments and new methods of planning, scheduling, executing, and controlling projects must be investigated.

\section{Conflicts of Interest}

The authors declare that they have no conflicts of interest.

\section{References}

[1] P. W. G. Morris, The Management of Projects, Thomas Telford, London, 1997.

[2] P. W. G. Morris, "Science, objective knowledge and the theory of project management," Civil Engineering, vol. 150, no. 2, pp. 82-90, 2002.

[3] J. Bennett and B. Fine, "Measurement of complexity in construction projects," in Department of Construction Management, University of Reading, 1980.
[4] K. A. Bubshait and W. J. Selen, Project Characteristics that Influence the Implementation of Project Management Techniques: a Survey, Project Management Institute, 1992.

[5] P. Bennett and S. Cropper, "Uncertainty and conflict: combining conflict analysis and strategic choice," Journal of Behavioral Decision Making, vol. 3, no. 1, pp. 29-45, 1990.

[6] K. Gidado, Numerical Index of Complexity in Building Construction to Its Effect on Production Time, University of Brighton, UK, 1993.

[7] T. M. Wozniak, Significance vs. Capability: “Fit for Use” Project Controls, AACE International Transactions, 1993.

[8] D. Baccarini, "The concept of project complexity-a review," International Journal of Project Management, vol. 14, no. 4, pp. 201-204, 1996.

[9] K. Remington, R. Zolin, and R. Turner, "A model of project complexity: distinguishing dimensions of complexity from severity," in Proceedings of the 9th International Research Network of Project Management Conference, Berlin, IRNOP, 2009.

[10] H. Parsons-Hann and K. Liu, "Measuring requirements complexity to increase the probability of project success," in Proceedings of the Seventh International Conference on Enterprise Information Systems - Volume 3: ICEIS, pp. 434-438, Miami, USA, 2005.

[11] L.-A. Vidal and F. Marle, "Understanding project complexity: implications on project management," Kybernetes, vol. 37, no. 8, pp. 1094-1110, 2008.

[12] S. C. Sommer and C. H. Loch, "Selectionism and learning in projects with complexity and unforeseeable uncertainty," Management Science, vol. 50, no. 10, pp. 1334-1347, 2004.

[13] H. Maylor, R. Vidgen, and S. Carver, "Managerial complexity in project-based operations: a grounded model and its implications for practice," Project Management Journal, vol. 39, 1_supplement, pp. S15-S26, 2008.

[14] T. Cooke-Davies, S. Cicmil, L. Crawford, and K. Richardson, "We're not in Kansas anymore, Toto: mapping the strange landscape of complexity theory, and its relationship to project management," Project Management Journal, vol. 38, no. 2, pp. 50-61, 2007.

[15] D. McLain, "Quantifying project characteristics related to uncertainty," Project Management Journal, vol. 40, no. 4, pp. 60-73, 2009.

[16] M. Bosch-Rekveldt, Y. Jongkind, H. Mooi, H. Bakker, and A. Verbraeck, "Grasping project complexity in large engineering projects: the TOE (technical, organizational and environmental) framework," International Journal of Project Management, vol. 29, no. 6, pp. 728-739, 2011.

[17] J. Geraldi, H. Maylor, and T. Williams, "Now, let's make it really complex (complicated) a systematic review of the complexities of projects," International Journal of Operations \& Production Management, vol. 31, no. 9, pp. 966-990, 2011.

[18] L.-A. Vidal, F. Marle, and J.-C. Bocquet, "Measuring project complexity using the analytic hierarchy process," International Journal of Project Management, vol. 29, no. 6, pp. 718727, 2011.

[19] T. Brady and A. Davies, "Managing structural and dynamic complexity: a tale of two projects," Project Management Journal, vol. 45, no. 4, pp. 21-38, 2014.

[20] M. Padalkar and S. Gopinath, "Are complexity and uncertainty distinct concepts in project management? A taxonomical examination from literature," International 
Journal of Project Management, vol. 34, no. 4, pp. 688-700, 2016.

[21] R. V. Ramasesh and T. R. Browning, "A conceptual framework for tackling knowable unknown unknowns in project management," Journal of Operations Management, vol. 32, no. 4, pp. 190-204, 2014.

[22] S. M. Qureshi and C. Kang, “Analysing the organizational factors of project complexity using structural equation modelling," International Journal of Project Management, vol. 33, no. 1, pp. 165-176, 2015.

[23] F. C. Saunders, A. W. Gale, and A. H. Sherry, "Conceptualising uncertainty in safety-critical projects: a practitioner perspective," International Journal of Project Management, vol. 33, no. 2, pp. 467-478, 2015.

[24] S. Sinha, A. I. Thomson, and B. Kumar, "A complexity index for the design process," WDK Publications, vol. 1, pp. 157$163,2001$.

[25] C. Brockmann and G. Girmscheid, Complexity of Megaprojects, in: CIB World Building Congress: Construction for Development: 14-17 May 2007, Cape Town International Convention Centre, South Africa, CIB, 2007.

[26] H. Mintzberg, Mintzberg on Management: Inside our Strange World of Organizations, Simon and Schuster, 1989.

[27] A. D. Hall, A Methodology for Systems Engineering, 1962.

[28] J. S. Russell, E. J. Jaselskis, and S. P. Lawrence, "Continuous assessment of project performance," Journal of Construction Engineering and Management., vol. 123, no. 1, pp. 64-71, 1997.

[29] P. R. Lawrence and J. W. Lorsch, "Differentiation and integration in complex organizations," Administrative Science Quarterly, vol. 12, no. 1, p. 1, 1967.

[30] E. Custovic, "Engineering management: old story, new demands," IEEE Engineering Management Review, vol. 43, no. 2, pp. 21-23, 2015.

[31] M. V. Tatikonda and S. R. Rosenthal, "Technology novelty, project complexity, and product development project execution success: a deeper look at task uncertainty in product innovation," IEEE Transactions on Engineering Management, vol. 47, no. 1, pp. 74-87, 2000.

[32] M. T. Pich, C. H. Loch, and A. D. Meyer, "On uncertainty, ambiguity, and complexity in project management," Management Science, vol. 48, no. 8, pp. 1008-1023, 2002.

[33] S. Ward and C. Chapman, "Transforming project risk management into project uncertainty management," International Journal of Project Management, vol. 21, no. 2, pp. 97105, 2003.

[34] G. Girmscheid and C. Brockmann, "The inherent complexity of large scale engineering projects," Project Perspectives, vol. 29, pp. 22-26, 2008.

[35] K. A. Richardson, "Managing complex organizations: complexity thinking and the science and art of management," Emergence: Complexity and Organization, vol. 10, p. 13, 2008.

[36] K. I. Gidado, "Project complexity: the focal point of construction production planning," Construction Management and Economics, vol. 14, no. 3, pp. 213-225, 1996.

[37] P. M. Blau and R. A. Schoenherr, The Structure of Organizations, Basic Books (AZ), 1971.

[38] J. M. Beyer and H. M. Trice, "A reexamination of the relations between size and various components of organizational complexity," Administrative Science Quarterly, vol. 24, no. 1, pp. 48-64, 1979.
[39] P. De Meyer, F. Maes, and A. Volckaert, "Emissions from international shipping in the Belgian part of the North Sea and the Belgian seaports," Atmospheric Environment, vol. 42, no. 1, pp. 196-206, 2008.

[40] A. R. Meyer and L. J. Stockmeyer, "The equivalence problem for regular expressions with squaring requires exponential space," in 13th Annual Symposium on Switching and Automata Theory (swat 1972), pp. 125-129, USA, October 1972.

[41] L. M. Corbett, J. Brockelsby, and C. Campbell-Hunt, Tackling Industrial Complexity, Tackling Industrial Complexity, Institute for Manufacturing, Cambridge, 2002.

[42] R. Dewar and J. Hage, "Size, technology, complexity, and structural differentiation: toward a theoretical synthesis," Administrative Science Quarterly, vol. 23, no. 1, pp. 111136, 1978.

[43] U. Steger, W. Amann, and M. L. Maznevski, Managing Complexity in Global Organizations, John Wiley \& Sons, 2007.

[44] H. Mintzberg, The Structuring of Organisations: a Synthesis of the Research, University of Illinois, Champaign, IL, USA, 1979.

[45] R. E. Levitt, J. Thomsen, T. R. Christiansen, J. C. Kunz, Y. Jin, and C. Nass, "Simulating project work processes and organizations: toward a micro-contingency theory of organizational design," Management Science, vol. 45, no. 11, pp. 14791495, 1999.

[46] E. C. Conforto, E. Rebentisch, and D. Amaral, "Learning the art of business improvisation," MIT Sloan Management Review, vol. 57, p. 8, 2016.

[47] J. Priest and J. Sanchez, Product Development and Design for Manufacturing: a Collaborative Approach to Producibility and Reliability, CRC Press, 2012.

[48] D. Woodward and H. M. College, Understanding Complexity: a Critique and Synthesis, Henley Management College, 1992.

[49] A. Jaafari, "Project management in the age of complexity and change," in Project Management Journal, vol. 34, no. 4, pp. 47-57, 2003.

[50] J. Pollack, "The changing paradigms of project management," International Journal of Project Management, vol. 25, no. 3, pp. 266-274, 2007.

[51] K. Remington and J. Pollack, Tools for Complex Projects, Routledge, 2016.

[52] J. D. Thompson, Organizations in Action: Social Science Bases of Administration, McGraw-Hill, New York City, NY, USA, 1967.

[53] J. R. Turner and R. A. Cochrane, "Goals-and-methods matrix: coping with projects with ill defined goals and/or methods of achieving them," International Journal of Project Management, vol. 11, no. 2, pp. 93-102, 1993.

[54] R. D. Stacey, Complexity and Creativity in Organizations, Berrett-Koehler Publishers, 1996.

[55] T. Williams and D. Hillson, "Editorial-PMI Europe 2001," International Journal of Project Management, vol. 20, no. 3, pp. 183-184, 2002.

[56] A. Kahane, Solving Tough Problems: an Open Way of Talking, Listening, and Creating New Realities, Berrett-Koehler Publishers, 2004.

[57] D. J. Snowden and M. E. Boone, "A leader's framework for decision making," Harvard Business Review, vol. 85, p. $68,2007$.

[58] A. J. Shenhar, Integrating Product Development and Project Management, in: 28th Annual Symposium of PMI, Project Management Institute, Chicago, IL, 1997. 
[59] A. J. Shenhar, "Strategic project management: the new framework," in PICMET '99: Portland International Conference on Management of Engineering and Technology. Proceedings Vol-1: Book of Summaries (IEEE Cat. No.99CH36310), pp. 382-386, Portland, OR, USA, July 1999.

[60] A. J. Shenhar and D. Dvir, "Toward a typological theory of project management," Research Policy, vol. 25, no. 4, pp. 607-632, 1996.

[61] T. B. Clift and M. B. Vandenbosch, "Project complexity and efforts to reduce product development cycle time," Journal of Business Research, vol. 45, no. 2, pp. 187-198, 1999.

[62] P. Declerck and R. P. et Eymery, Le management et l'analyse des projets, Editions Hommes et Techniques, Paris, France, 1976.

[63] T. Little, "Context-adaptive agility: managing complexity and uncertainty," IEEE Software, vol. 22, no. 3, pp. 28-35, 2005.

[64] T. M. Williams, "The need for new paradigms for complex projects," International Journal of Project Management, vol. 17, no. 5, pp. 269-273, 1999.

[65] A. J. Shenhar, "One size does not fit all projects: exploring classical contingency domains," Management Science, vol. 47, no. 3, pp. 394-414, 2001.

[66] R. Atkinson, L. Crawford, and S. Ward, "Fundamental uncertainties in projects and the scope of project management," International Journal of Project Management, vol. 24, no. 8, pp. 687-698, 2006.

[67] R. Müller, J. G. Geraldi, and J. R. Turner, "Linking complexity and leadership competences of project managers," in Proceedings of IRNOP VIII (International Research Network for Organizing by Projects) Conference, Brighton, UK, CD-ROM. Universal Publishers, 2007.

[68] O. Perminova, M. Gustafsson, and K. Wikström, "Defining uncertainty in projects-a new perspective," International Journal of Project Management, vol. 26, no. 1, pp. 73-79, 2008.

[69] T. Williams, "Assessing and moving on from the dominant project management discourse in the light of project overruns," IEEE Transactions on Engineering Management, vol. 52, no. 4, pp. 497-508, 2005.

[70] J. H. Payne, "Management of multiple simultaneous projects: a state-of-the-art review," International Journal of Project Management, vol. 13, no. 3, pp. 163-168, 1995.

[71] A. Laufer, G. R. Denker, and A. J. Shenhar, "Simultaneous management: the key to excellence in capital projects," International Journal of Project Management, vol. 14, no. 4, pp. 189-199, 1996.

[72] A. K. Pundir, L. Ganapathy, and N. Sambandam, "Towards a complexity framework for managing projects," Emergence: Complexity and Organization, vol. 9, p. 17, 2007.

[73] H. Singh and A. Singh, "Principles of complexity and chaos theory in project execution: a new approach to management," Cost Engineering, vol. 44, p. 23, 2002. 


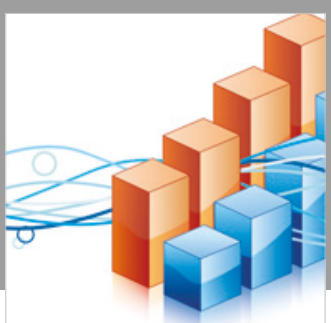

Advances in

Operations Research

\section{-n-m}
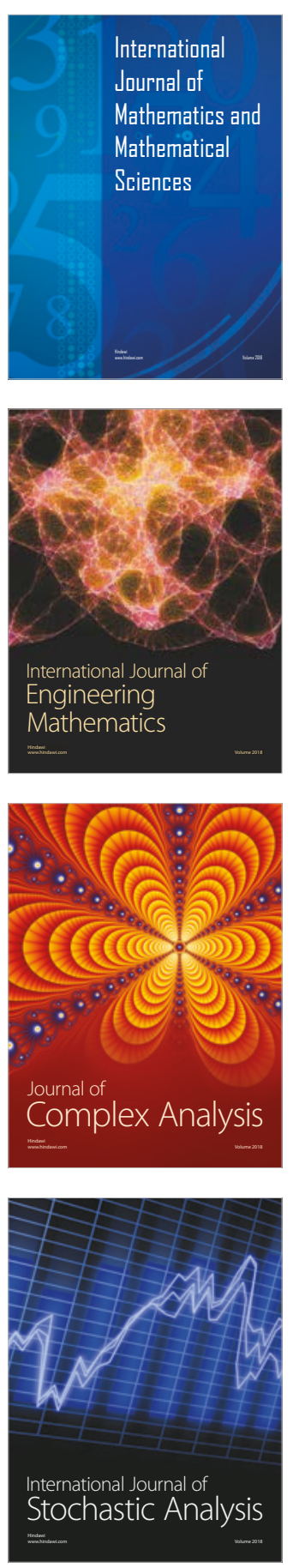
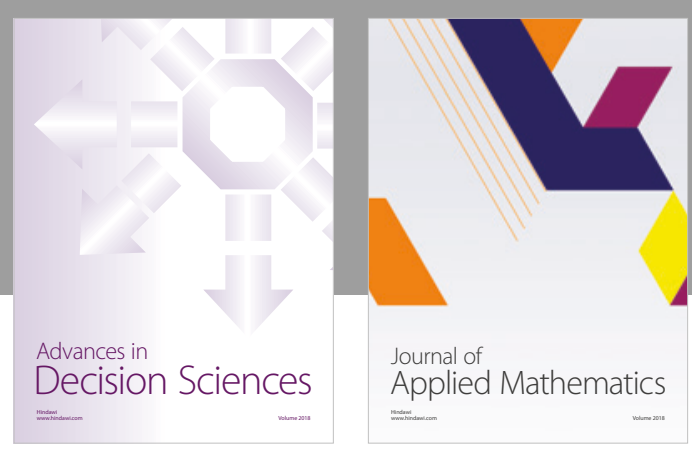

Journal of

Applied Mathematics
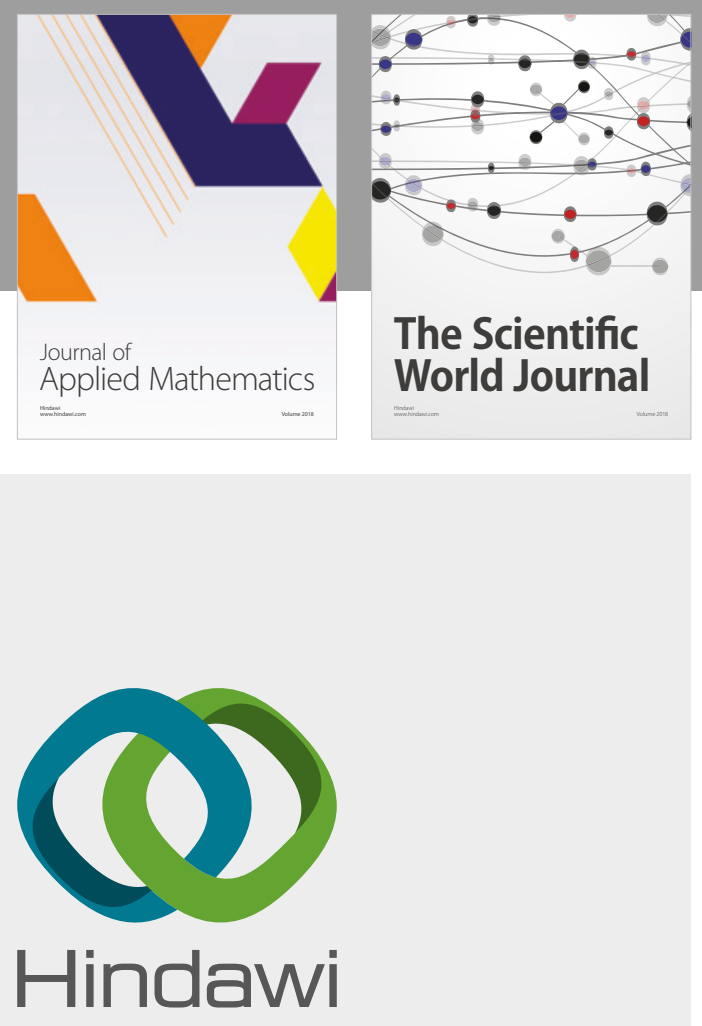

Submit your manuscripts at

www.hindawi.com

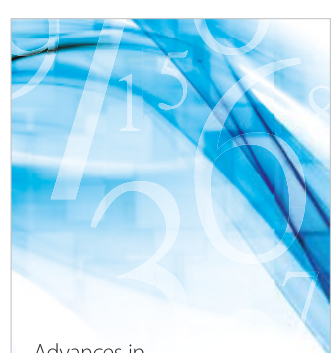

Advances in
Numerical Analysis
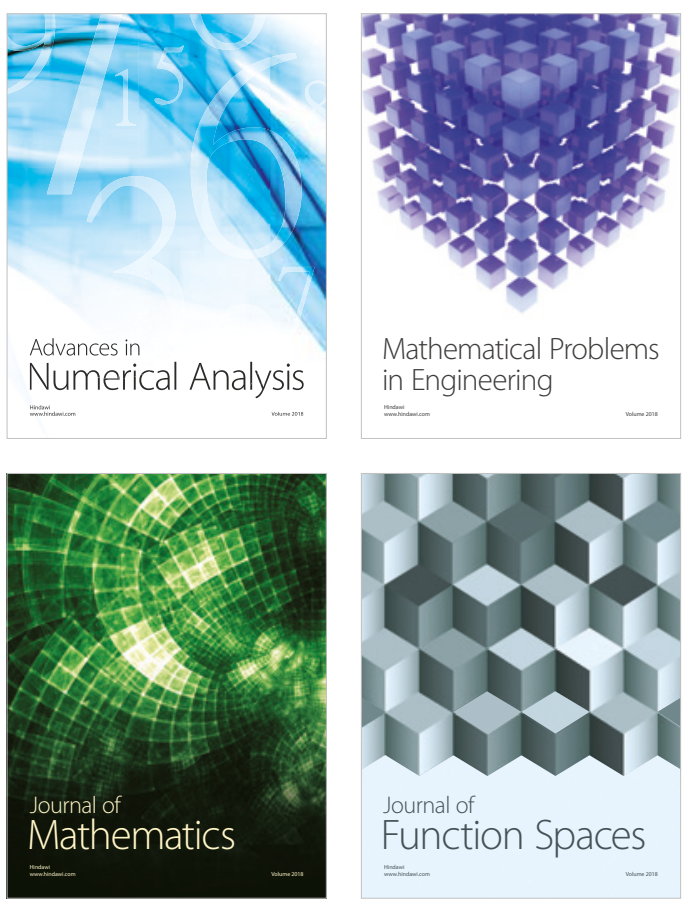

Mathematical Problems in Engineering

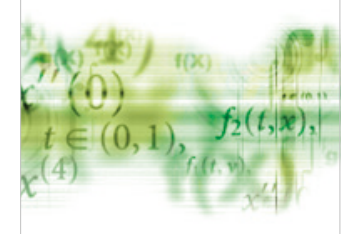

International Journal of

Differential Equations

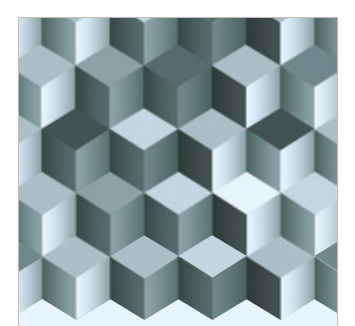

Journal of

Function Spaces
The Scientific

World Journal

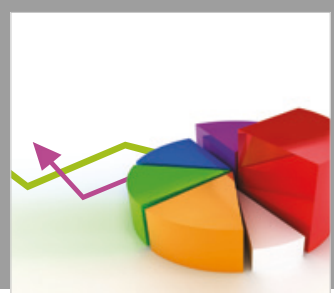

Journal of

Probability and Statistics
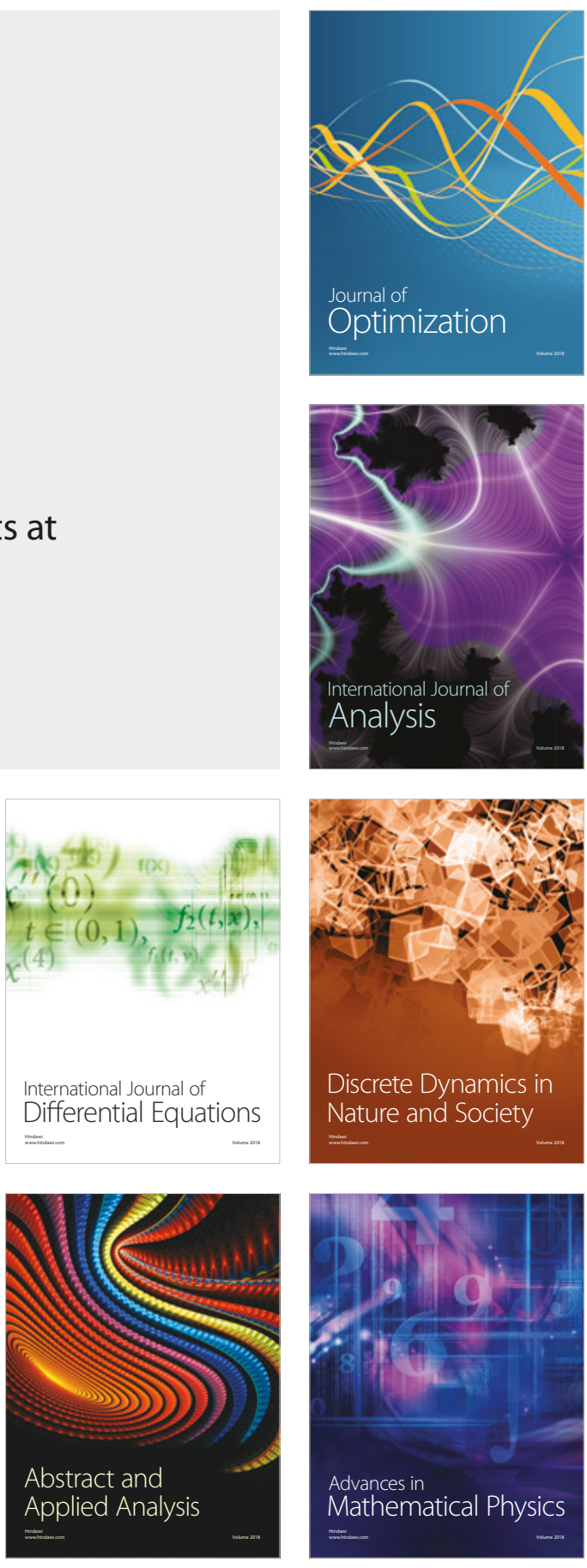